\title{
Worster-Drought syndrome
}

INSERM

\section{Source}

INSERM. (1999). Orphanet: an online rare disease and orphan drug data base. WorsterDrought syndrome. ORPHA:3465

Worster-Drought syndrome (WDS) is a form of cerebral palsy characterized by congenital pseudobulbar (suprabulbar) paresis manifesting as selective weakness of the lips, tongue and soft palate, dysphagia, dysphonia, drooling and jaw jerking. 